University of Nebraska - Lincoln

DigitalCommons@University of Nebraska - Lincoln

USDA Wildlife Services - Staff Publications

U.S. Department of Agriculture: Animal and Plant Health Inspection Service

2012

\title{
A novel bipolar electric fence for excluding white-tailed deer from stored livestock feed
}

\author{
G. E. Phillips \\ USDA/APHIS/Wildlife Services/National Wildlife Research Center
}

M. J. Lavelle

USDA/APHIS/WS National Wildlife Research Center, michael.j.lavelle@aphis.usda.gov

Justin W. Fischer

USDA/APHIS/WS National Wildlife Research Center, Justin.w.fischer@aphis.usda.gov

Joshua J. White

South Dakota State University, Joshua.White@sdstate.edu

Scott J. Wells

University of Minnesota, swells@umn.edu

See next page for additional authors

Follow this and additional works at: https://digitalcommons.unl.edu/icwdm_usdanwrc

Part of the Life Sciences Commons

Phillips, G. E.; Lavelle, M. J.; Fischer, Justin W.; White, Joshua J.; Wells, Scott J.; and VerCauteren, K. C., "A novel bipolar electric fence for excluding white-tailed deer from stored livestock feed" (2012). USDA Wildlife Services - Staff Publications. 1177.

https://digitalcommons.unl.edu/icwdm_usdanwrc/1177

This Article is brought to you for free and open access by the U.S. Department of Agriculture: Animal and Plant Health Inspection Service at DigitalCommons@University of Nebraska - Lincoln. It has been accepted for inclusion in USDA Wildlife Services - Staff Publications by an authorized administrator of DigitalCommons@University of Nebraska - Lincoln. 


\section{Authors}

G. E. Phillips, M. J. Lavelle, Justin W. Fischer, Joshua J. White, Scott J. Wells, and K. C. VerCauteren 


\title{
A novel bipolar electric fence for excluding white-tailed deer from stored livestock feed ${ }^{\mathbf{1}}$
}

\author{
G. E. Phillips,* M. J. Lavelle,* J. W. Fischer,* J. J. White,*2 S. J. Wells, $\dagger$ and K. C. VerCauteren*3 \\ *USDA/APHIS/Wildlife Services/National Wildlife Research Center, Fort Collins, CO 80521 and $\uparrow$ Department of \\ Veterinary Population Medicine and Center for Animal Health and Food Safety, University of Minnesota, Saint Paul 55108
}

\begin{abstract}
Where cattle (Bos taurus) and freeranging white-tailed deer (Odocoileus virginianus) coexist, they frequently share space and resources, potentially resulting in damage to stores of livestock feed and risk of interspecies disease transmission. Preventing use of stored feed by deer can be an important objective in farm management, depending on amount of damage experienced and perceived risk of disease transmission. Woven wire fences (2.4 to $3.0 \mathrm{~m}$ high) are generally considered to be the most effective means for excluding deer. However, rapidly deployable temporary means of excluding deer could be useful, especially during late winter when deer are most physiologically stressed and motivated to consume feed meant for cattle. Thus, the objective of this study was to evaluate a novel 1.2-m-tall electric fence consisting of 4 strands of bipolar tape (not requiring separate ground wires or animal contact with ground) for excluding deer from artificially established feed piles during late winter 2008 in northwestern
\end{abstract}

Minnesota. To induce deer to pause, investigate the fence, and receive negative stimuli before attempting to jump the fence, the bipolar tape was baited with a viscous fluid attractive to deer. The fence was estimated to be $>80 \%$ effective at reducing deer presence at feed piles (10 treatment sites and 11 control sites) given the late winter to early spring conditions. Despite the efficacy, using the fence as a primary means of protecting stored feed from deer in areas with known disease transmission risk (e.g., presence of bovine tuberculosis) is not recommended because risk could remain unacceptably high if even low numbers of deer access stored feed. Yet, the fence could be effective as immediate protection of stored feed in winter before a more permanent and effective deterrence strategy, such as woven-wire fencing, could be installed during the subsequent summer. The fence would also be effective for reducing deer depredation of stored feed, as well as gardens, small orchards, or other localized or seasonal resources.

Key words: cattle, depredation, electric fence, stored feed, white-tailed deer

(C) 2012 American Society of Animal Science. All rights reserved.

J. Anim. Sci. 2012.90:4090-4097

doi:10.2527/jas2011-4619

\section{INTRODUCTION}

White-tailed deer populations are at historically large numbers across much of the United States, creating

\footnotetext{
${ }^{1}$ The authors thank B. Knust, A. Paul, T. Ruby, P. Wolf, Minnesota Board of Animal Health, Agassiz National Wildlife Refuge, and Minnesota DNR for assistance during the study. We also thank the many private landowners who graciously provided access to property. We thank M. Carstensen, S. Shriner, and M. West for comments on drafts of the manuscript. This study was supported in part by the 2008 Minnesota Rapid Agricultural Response Fund. Mention of companies or commercial products does not imply recommendation or endorsement by USDA. Product names are mentioned solely to report factually on available data and to provide specific information.

${ }^{2}$ Present address: Department of Wildlife and Fisheries Sciences, South Dakota State University, Brookings, SD 57007.

${ }^{3}$ Corresponding author: Kurt.C.VerCauteren@aphis.usda.gov

Received August 22, 2011.

Accepted March 16, 2012.
}

conflicts regarding agricultural and landscaping damage (depredation), transmissible diseases carried by deer, and risk to public safety (Côté et al., 2004). Deer can cause substantial damage to haylage and silage stored on the ground in large plastic tubes (VerCauteren et al., 2003). Stored feed losses result from spoilage due to deer penetrating bags with their hooves and from contamination with deer feces and urine at the open end of bags. Cervids also damage hay bales stored in fields and yards (Brook, 2009). In addition, the risk of disease transmission increases when animals congregate and share resources (Miller et al., 2003; Miller et al., 2004; Wobeser, 2006). For example, shared feed is thought to be the most plausible route of transmitting Mycobacterium bovis (the causal agent of bovine tuberculosis; bTB) from deer to cattle (Palmer et al., 2004; O'Brien et al., 2006) and vice versa (Carstensen and DonCarlos, 
2011). Economically, the recent 2005 outbreak of bTB in Minnesota has cost the USDA nearly $\$ 70$ million, Minnesota Board of Animal Health \$12.5 million, and the Minnesota Department of Natural Resources \$3.5 million on bTB-related expenditures to eradicate the disease (Thompson, 2010). Thus, farmers experiencing substantial depredation of stored feed or who operate in areas with known deer-to-cattle disease transmission risk, as well as various government agencies, could benefit by excluding deer from stored feed.

Well-maintained permanent woven-wire fencing, such as that used to contain captive cervids, is the most dependable method for excluding deer (VerCauteren et al., 2006b, 2010). However, in some instances, easily repositioned, temporary, or seasonal exclusion fencing of deer may be useful, particularly as an intermediate step toward a more permanent and effective deterrence in response to deer use of stored feed. Therefore, the objective of this study was to estimate the extent to which a novel electric fence, erected around stored feed, might reduce presence of deer at feed sites. Reduced presence of deer could, thereby, potentially reduce depredation and lower risk of indirect transmission of bTB from deer to cattle.

\section{MATERIALS AND METHODS}

The Institutional Animal Care and Use Committee of the USDA, Animal and Plant Health Inspection Service, Wildlife Services, National Wildlife Research Center approved all procedures used in this study (QA-1529).

\section{Study Area}

The study was conducted within a $2,550-\mathrm{km}^{2}$ area in Kittson, Marshall, and Roseau counties in northwestern Minnesota. The region consists primarily of agricultural land, livestock operations, and fragmented hardwood forest. Mean temperature and snowfall (1971 to 2000) for February, March, and April were $-13.1,-5.1$, and $4.6^{\circ} \mathrm{C}$, respectively, and 16.3, 12.7, and $3.6 \mathrm{~cm}$, respectively (Midwestern Regional Climate Center, 2008). Estimated 2007 preharvest deer densities for these 3 counties were 2 to 3, 2 to 6 , and 2 to 3 deer $/ \mathrm{km}^{2}$, respectively (E. Dunbar, Minnesota Department of Natural Resources, personal communication).

\section{Study Design and Data Acquisition}

The study was initiated during the most foodstressed period of the year for deer (late winter) to provide a substantive test of the fence, and using a 2-period comparative change design (Manly, 1992), deer presence was monitored at a sample of 21 artificial feed sites during a pretreatment period and a treatment period. Treatment involved installing fences at approximately one-half of the sites between periods. The pretreatment period began on February 28, 2008, whereas fences were installed from March 16 through 19 (the beginning of the treatment period was designated as March 18 for the unprotected sites), with the treatment period ending on April 5, 2008. Sites were ranked according to deer use measured during the first week of the pretreatment period. The site with greatest use was randomly allocated to 1 of 2 treatment groups, and then group allocation was alternated among remaining sites from greatest to least use. Ten sites were assigned to protected (fenced) and 11 to unprotected treatment groups.

Study sites were on privately owned land, based on Minnesota Department of Natural Resources reports of deer damage to stored feed, landowner reports of deer using stored feed, and/or visual evidence of concentrations of deer (e.g., well-traveled deer trails). All sites were $<100 \mathrm{~m}$ from areas of contiguous woodland, which provided cover for deer. An artificial feed pile was created at each site consisting of $25 \mathrm{~kg}$ of looselypiled, third-cutting alfalfa, $13 \mathrm{~kg}$ of whole-kernel corn, and approximately $4 \mathrm{~L}$ of top-dressed raw molasses in an attempt to provide a highly attractive alternative to nearby feed sources. Each feed pile was encircled with 8 fiberglass poles $($ diameter $=1.3 \mathrm{~cm}$, length $=1 \mathrm{~m})$ topped with a wrap of reflective tape to provide a standardized 7-m-diameter sampling zone for all study sites. It was assumed that deer entering the sampling zone were there to feed. The artificial feed piles were spaced between 2.1 and $15.4 \mathrm{~km}($ mean $=7.1 \mathrm{~km})$ to promote independence among sites.

At protected sites, electric fencing was installed around the perimeter of a 20 by $20 \mathrm{~m}$ exclosure area containing the centrally-located feed pile. An easyto-install fence product was used that incorporated 5 positively and 5 negatively charged stainless steel wires into a single ribbon of 3.8-cm-wide "bipolar" tape woven from ultraviolet-resistant polyethylene threads (HorseGuard, Montgomery, IL). Fences consisted of 4 strands of bipolar tape hung at 30,60,90, and $120 \mathrm{~cm}$ heights, resulting in an overall height of $1.2 \mathrm{~m}$. This bipolar tape was stretched between insulators hung on $1.83-\mathrm{m}$ steel t-posts on corners and gate posts and fiberglass in-line posts approximately $7 \mathrm{~m}$ apart. Each exclosure fence was powered by a single, 12-V deepcycle marine battery and a Speedrite 3000 energizer (TruTest Limited, Auckland, New Zealand), with maximum output of $3 \mathrm{~J}$, that was attached to corner or gate posts. To facilitate aversive conditioning of deer (Kinsey, 1976; Hygnstrom and Craven, 1988; Jordan and Richmond, 1992), premixed bait (4 parts each molasses and peanut butter, 1 part each grain alcohol, peanut oil, and water) was applied to the tape with a squeeze bottle. 
Imagery data were collected at each site using Reconyx Silent Image cameras (model PM35; field of view $=40^{\circ}$ for lens, illuminator, and motion detector; maximum detection range $=30 \mathrm{~m}$; Reconyx, Inc., Holmen, WI) powered by nonrechargeable lithium AA batteries, which last longer in cold weather than alternative batteries. Reconyx cameras were equipped with an infrared illuminator which minimized the potential negative effect of cameras on deer activity. To further ensure against loss of data, 2 cameras/ site were positioned side-by-side within a plywood enclosure mounted on 2 steel t-posts, $9 \mathrm{~m}$ directly south of the center of the feed pile. The plywood camera enclosures minimized likelihood of moisture obscuring the field of view of cameras and the north-facing orientation minimized potential for overexposed images due to position of the sun. Cameras were programmed to take a photograph every $15 \mathrm{~min}$ throughout the study. Resulting imagery was viewed using Silent Image MapView Image Management Software (Reconyx, Inc., Holmen, WI), and deer within the sampling area were quantified. Once every $4 \mathrm{~d}$, batteries of cameras and fence chargers were checked, data cards were exchanged, feed was added to maintain the desired amount, bait was reapplied to fences, and an electric fence tester was used to ensure fences were operating correctly.

\section{Calculations and Statistical Analyses}

One camera/site was randomly selected as a data source and numbers of deer inside the sampling zone were counted for each image. Deer were counted even if they were only partially inside the sampling zone. A response variable was quantified representing site $x$ period-specific count of deer within the sampling zone, standardized to a $24-\mathrm{h}$ interval (count/d):

$$
\bar{\theta}_{j k}=24 \sum_{l=1}^{\mathrm{T}_{j k}} \theta_{j k l} / \sum_{l=1}^{\mathrm{T}_{j k}} \mathrm{M}_{j k l},
$$

where $\theta_{j k l}=$ count of deer within the sampling zone from image $l$ during period $k$ at site $j ; \mathrm{M}_{j k l}=0.25$ or $0 \mathrm{~h}$ if the camera was functional or nonfunctional, respectively; and $\mathrm{T}_{j k}=$ total possible number of 15-min intervals/ period by site (accounting for camera maintenance). Cameras were considered nonfunctional if no image was recorded at scheduled 15-min intervals (e.g., battery failure), the sampling zone was partially obscured by fog or snow, or if the camera became misaligned by animal activity or support instability. All 24-h intervals with $\leq 12 \mathrm{~h}$ of camera function were excluded to minimize temporal bias in counts. Furthermore, to remove influence of fence installation activity on deer presence, the 24 -h period ( 0700 to $0659 \mathrm{~h}$ ) within which fencing was installed was excluded for each protected site. The response variable was an index of deer presence at, or use of, artificial feed piles (deer index), and did not represent a daily rate of individual deer presence because individual deer were not identifiable.

The GLIMMIX procedure (SAS Inst. Inc., Cary, NC) was used to estimate the efficacy of the electric fence design for reducing deer presence at artificial feed piles. The global model was $\bar{\theta}_{j k m}=\operatorname{group}_{m_{-}}+\operatorname{period}_{k}+$ $(\text { group } \times \text { period })_{m k_{-}}+\mathrm{DC}_{j}+\mathrm{DHA}_{j}$, where $\bar{\theta}_{j k m}$ was the expected value of $\bar{\theta}_{j k}$ in the $m$ th treatment group; group, period, and group $\times$ period interaction were categorical fixed effects; and distance to cover (DC) and distance to human activity (DHA) were site-specific covariates describing the nearest distance to cover and to human activity, respectively. The global model was used to select among 7 residual variance-covariance structures, allowing for different combinations of correlated errors induced by repeated measures on sites and heterogeneity of variances, and a null model with only total residual variance (Table 1). Restricted maximum likelihood and Akaike's information criterion adjusted for small samples $\left(\mathbf{A I C}_{\boldsymbol{C}}\right.$ ) were used for covariance model selection (Littell et al., 2006). Using the covariance model indicated by minimum $\mathrm{AIC}_{C}$, reduced models in the fixed effects were evaluated by removing covariates DC and DHA singly and together, where the most reduced model included group, period, and group $\times$ period. Maximum likelihood was used for fixed effects model selection (Burnham and Anderson 2002) and the minimum-AIC ${ }_{C}$ model was then reevaluated using REML for parameter estimation and inference (Littell et al., 2006). Proportional weight of evidence $\left(\boldsymbol{w}_{\boldsymbol{i}}\right)$ supporting each model was reported, where $\Sigma w_{i}=1$ over each of the covariance and fixed effects sets of candidate models (Burnham and Anderson, 2002).

From the least $\mathrm{AIC}_{C}$ model, (group $\times$ period) $m k$ marginal means $\left(\hat{\theta}_{m k}\right.$; Milliken and Johnson, 2009) were estimated with $95 \%$ confidence intervals (CI) and values of $\hat{\theta}_{m k}$ were contrasted to estimate treatment effect of the fence by

$$
\hat{\delta}_{\text {interaction }}=\left(\hat{\theta}_{f 2}-\hat{\theta}_{u 2}\right)-\left(\hat{\theta}_{f 1}-\hat{\theta}_{u 1}\right) \text {, }
$$

where $m=f$ or $u$ for protected or unprotected treatment group, and $k=1$ or 2 for pretreatment or treatment period. Given the study design, the interaction of group $\times$ period and the related linear contrast $\hat{\delta}_{\text {interaction }}$ were of primary importance in estimating overall treatment effect of the fence for reducing deer presence at feed piles. The interaction contrast represented the mean difference between unprotected and protected sites in Period 2 after accounting for differences in Period 1, where a negative value would indicate relatively greater declines in Period 2 for protected sites. A one-sided, upper 95\% CI on $\hat{\delta}_{\text {interaction }}$ was reported, consistent with an a priori expectation that fencing would reduce deer use of artificial feed piles (i.e., $\hat{\delta}_{\text {interaction }}<0$ ). 
Post hoc simple main effects were estimated with 95\% CI (2-sided, as these analyses were unplanned), where levels of 1 fixed effect were contrasted at each level of the other fixed effect in the presence of interaction (Quinn and Keough, 2002; O'Rourke et al., 2005). Simple main effects contrasts included difference between Periods 2 and 1 within the protected group: $\hat{\delta}_{f 2-f 1}=\hat{\theta}_{f 2}-\hat{\theta}_{f 1}$; difference between Periods 2 and 1 within the unprotected group: $\hat{\delta}_{u 2-u 1}=\hat{\theta}_{u 2}-\hat{\theta}_{u 1}$; difference between protected and unprotected groups within Period 1: $\hat{\delta}_{f 1-u 1}=\hat{\theta}_{f 1}-\hat{\theta}_{u 1}$; and difference between protected and unprotected groups within Period 2: $\hat{\delta}_{f 2-u 2}=\hat{\theta}_{f 2}-\hat{\theta}_{u 2}$.

It is often desirable to express treatment effect as percentage of change relative to the control state (i.e., relative treatment effect). There is no unambiguous single expression for percentage of change in a response variable caused by treatment effect for the 2-period comparative change design because $\hat{\delta}_{\text {interaction }}$ is a function of all 4 group $\times$ period means; therefore, expressing $\hat{\delta}_{\text {interaction }}$ as a percentage of any one of them ignores information provided by the others. However, given the a priori expectation that deer presence would decline in Period 2 relative to all other group $\times$ period cells, it was most appropriate to reference the interaction contrast estimate against the best estimate of the unprotected period-2 control mean response adjusted for differences between groups in the pretreatment period $\left(\hat{\theta}_{u 2}^{\prime}\right)$. Then, $\hat{\theta}_{u 2}^{\prime}=\hat{\theta}_{u 2}+\hat{\delta}_{f 1-u 1}=\hat{\theta}_{f 2}-\hat{\delta}_{\text {interaction }}$ and $100 \times \hat{\delta}_{\text {interaction }} /\left(\hat{\theta}_{f 2}-\hat{\delta}_{\text {interaction }}\right)$ provides a measure of relative change in deer presence $(\%)$, or relative treatment effect, accounting for pretreatment differences.

\section{RESULTS}

Pretreatment and treatment periods lasted $19 \mathrm{~d}$ each. Graphically, presence of deer at artificial feed piles appeared similar between treatment groups during the pretreatment period, with some indication of decline late in the period (Figure 1). After fences were installed, the deer index dropped abruptly for the protected group and remained low throughout the treatment period. Meanwhile, the index for the unprotected group gradually converged to levels similar to the protected group by the end of the treatment period.

The highest ranked covariance structures for the global model included a separate variance for each period and a between-period covariance (Table 1), and this covariance structure was used for fixed-effects model selection and final parameter estimation. In comparisons of fixed effects models, the group|period model (where "|" indicated a model including both main effects and their interaction) had stronger weight of evidence $\left(w_{i}=\right.$ 0.63 , Table 2) than those including covariates DC and DHA, and the simpler model was used for parameter estimation (after refitting using REML).

Estimates of group $\times$ period means $\left(\hat{\theta}_{m k}\right)$ from the group|period model suggested that protected sites had less deer presence than unprotected sites in the treatment

Table 1. Model selection among residual variance-covariance (Var-Covar) structures using the most general fixedeffects model ${ }^{1}$ for comparing an index of deer presence at artificial feed sites protected or not protected by electric fences between February 28 and April 5, 2008 in northwestern Minnesota

\begin{tabular}{|c|c|c|c|c|c|}
\hline Var-Covar structure $^{2}$ & -2 log-likelihood & $\kappa^{3}$ & $\mathrm{AIC}_{C}{ }^{4}$ & $\Delta \mathrm{AIC}_{C}{ }^{5}$ & $w_{i}^{6}$ \\
\hline UN (Cholesky) & 377.90 & 3 & 384.65 & 0 & 0.66 \\
\hline UN (Cholesky) by group & 371.21 & 6 & 386.10 & 1.45 & 0.32 \\
\hline VC by period & 387.99 & 2 & 392.35 & 7.70 & 0.01 \\
\hline $\mathrm{VC}$ by group by period & 383.21 & 4 & 392.50 & 7.85 & 0.01 \\
\hline $\operatorname{AR}(1)$ & 403.03 & 2 & 407.39 & 22.7 & $<0.01$ \\
\hline Total residual variance only & 406.31 & 1 & 408.43 & 23.8 & $<0.01$ \\
\hline
\end{tabular}

${ }^{1}$ Fixed-effects model included group [protected (sites allocated for protection by electric fence during treatment period) vs. unprotected (sites not protected by fence)], period [pretreatment (before fence installation or through March 17 for unprotected sites) vs. treatment (after fence installation at 10 sites or after March 17 for unprotected sites)], group $\times$ period interaction, DC [covariate for distance from artificial feed site to nearest cover (m)], and DHA [covariate for distance to nearest human activity (m)].

${ }^{2} \mathrm{UN}($ Cholesky $)=$ general unstructured residual variance-covariance matrix parameterized through its Cholesky root, with separate estimates of variance for each period and a covariance between periods for each group $(\kappa=6$ covariance parameters estimated for model $)$ and for groups pooled $(\kappa=3)$; AR $(1)=$ first order autoregressive structure for residuals where a common variance was estimated for both periods along with a correlation coefficient between periods for each group $(\kappa=4)$ and for groups pooled $(\kappa=2)$; and $\mathrm{VC}=$ residual variance components estimated separately by levels of group $(\kappa=2)$, period $(\kappa=2)$, or group $\times$ period interaction $(\kappa=4)$, without modeling covariance of residuals associated with repeated measures at sites. The total-residual-variance-only model represents the null case of traditional analysis of variance, dependent on assumptions of independent residuals and homogeneous variances $(\kappa=1)$.

${ }^{3}$ Number of variance-covariance parameters estimated in models.

${ }^{4} \mathrm{AIC}_{C}=$ Akaike's Information Criterion corrected for small sample size, where sample size was reduced by number of fixed effects parameters (6) estimated in the global model $(n=36)$.

${ }^{5} \Delta \mathrm{AIC}_{C}=$ distance of a model from the minimum- $\mathrm{AIC}_{C}$ model.

${ }^{6}$ Proportional weight of evidence in support of a model. 


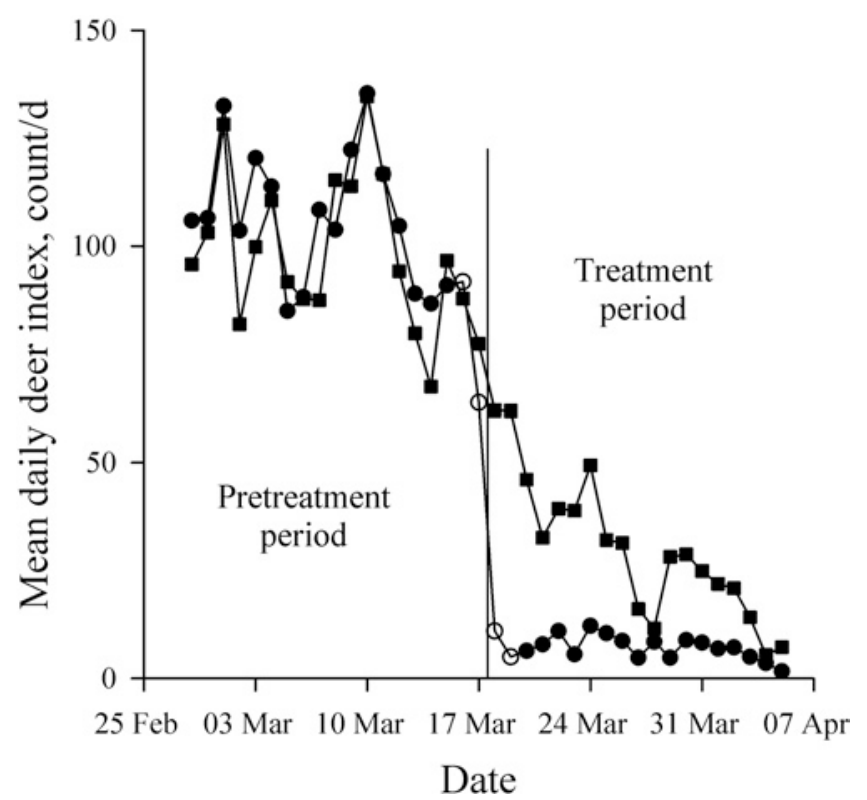

Figure 1. Trends in mean daily index of deer presence from camera surveillance at artificial feed piles established to test efficacy of baited bipolar electric fencing for deterring deer from stored feed in northwestern Minnesota, between February 28 and April 5, 2008. Treatment groups consisted of 10 sites allocated to receive electric fencing (protected, circles) during the treatment period and 11 control sites (unprotected, squares) that were not fenced. A vertical line delineates pretreatment and treatment periods for the unprotected group only. For the protected group, fences were installed during a 4-d period (March 16 to 19, 2008 indicated by open circles).

period (Figure 2 and Table 3). Estimated treatment effect attributable to fences $\left(\hat{\delta}_{\text {interaction }}\right)$ was -35.3 count $/ \mathrm{d}(P=$ 0.045; Table 3), corresponding to a relative treatment effect of $83 \%$ reduction in deer presence. Variance among sites was 3,098 count $^{2} / \mathrm{d}^{2}$ in the pretreatment period and 321 count $^{2} / \mathrm{d}^{2}$ in the treatment period (data not shown). Covariance between periods was 658 count ${ }^{2} / \mathrm{d}^{2}$, corresponding to a correlation coefficient of 0.66 (data not shown).

The post hoc analyses of simple main effects confirmed graphical depiction (Figures 1 and 2) of a strong period effect. Deer presence was less $(P<0.001)$ in the treatment period than the pretreatment period for

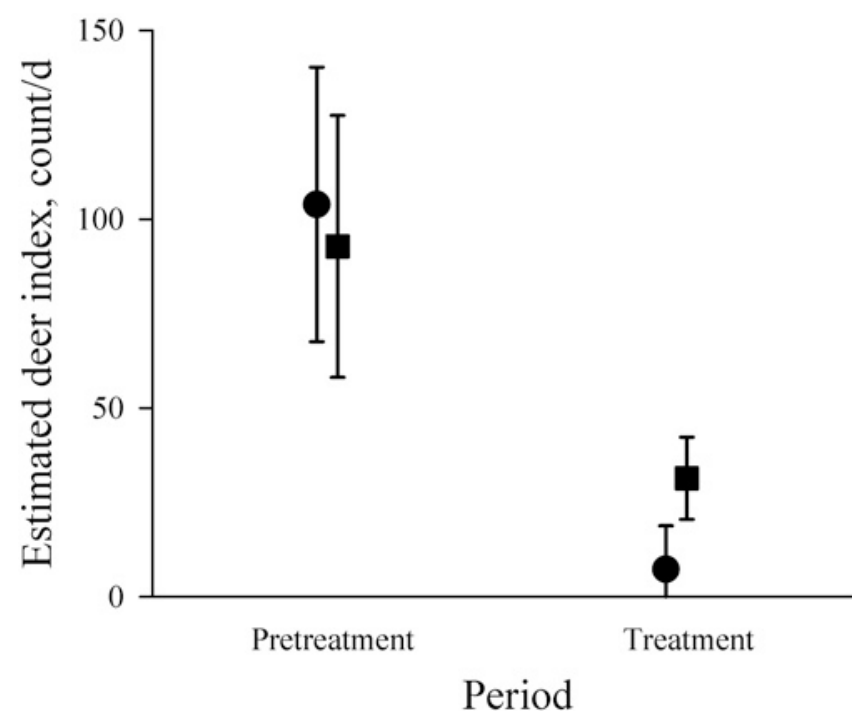

Figure 2. Model-estimated daily index of deer presence from camera surveillance at artificial feed piles established to test efficacy of baited bipolar electric fencing for deterring deer from stored feed in northwestern Minnesota, between February 28 and April 5, 2008. Error bars are 95\% confidence intervals estimated from the model including terms for group, period, and group $\times$ period interaction. Treatment groups consisted of 10 sites allocated to receive electric fencing (protected, circles) during the treatment period and 11 control sites (unprotected, squares) that were not fenced.

both protected and unprotected groups. Despite this confounding factor, the simple main effect for treatment $\left(\hat{\delta}_{f 2-u 2}\right)$ indicated a $77 \%$ reduction $(-24.1 \mathrm{count} / \mathrm{d}, P=$ $0.005)$ in deer presence at protected sites (i.e., without adjusting for small pretreatment differences; Table 3 ).

Efficacy of the fence is further supported by the pattern of change over time in deer presence (Figure 1). Decline in the index was abrupt at protected sites after fences were installed and remained low throughout the treatment period (not different from $0, P=0.201$ ), but the index declined gradually for unprotected sites.

Distance to cover and DHA (houses and outbuildings) were not strongly related $(P>0.5)$ to presence of deer at our feed piles. From camera data, it was observed that deer activity at the artificial feed piles was almost completely crepuscular or nocturnal, whereas nearby

Table 2. Selection among fixed-effects models for estimating an index of deer presence, and efficacy of electric fences to reduce deer presence, at artificial feed sites between February 28 and April 5, 2008 in northwestern Minnesota

\begin{tabular}{|c|c|c|c|c|c|}
\hline Model $^{1}$ & -2 log-likelihood & $\kappa^{2}$ & $\mathrm{AIC}_{C}{ }^{3}$ & $\Delta \mathrm{AIC}_{C}{ }^{4}$ & $w_{i}^{5}$ \\
\hline group|period + DHA & 392.43 & 8 & 412.80 & 2.57 & 0.18 \\
\hline group|period + DC + DHA & 391.91 & 9 & 415.54 & 5.31 & 0.04 \\
\hline
\end{tabular}

${ }^{1}$ Fixed-effects included group [protected (sites allocated for protection by electric fence during treatment period) vs. unprotected (sites not protected by fence)], period [pretreatment (before fence installation or through March 17 for unprotected sites) vs. treatment (after fence installation at 10 sites or after March 17 for unprotected sites)], group $\times$ period interaction, DC [covariate for distance from artificial feed site to nearest cover (m)], and DHA [covariate for distance to nearest human activity $(\mathrm{m})]$. "Group|period" indicates that both main effects and interaction were in the model.

${ }^{2}$ Number of fixed-effect and variance-covariance parameters estimated in models.

${ }^{3} \mathrm{AIC}_{C}=$ Akaike's Information Criterion corrected for small sample size $(\mathrm{n}=42)$.

${ }^{4} \Delta \mathrm{AIC}_{C}=$ distance of a model from the minimum- $\mathrm{AIC}_{C}$ model.

${ }^{5}$ Proportional weight of evidence in support of a model. 
human activity was mostly diurnal; thus, temporal segregation of deer and human activity may have diluted effects of human activity on deer presence. Additionally, site maintenance was completely diurnal, ensuring little influence on deer presence at feed piles.

Results of covariance model selection indicated violation of standard assumptions required for validity of general linear modeling (e.g., regression, ANOVA, analysis of covariance). Both heterogeneity in variances and correlation in residual errors were discovered between periods. Historically, response or explanatory variables have been transformed to ensure homogeneity of variances, but transformations cannot account for correlation among residuals and may complicate interpretation of results. By identifying a parsimonious covariance structure among reasonable alternatives, estimates of variances, covariances, and correlation coefficients (mathematical functions of variances and covariances) were integrated into estimates of fixed-effect and treatment-effect variances. Resulting estimates accounted for heterogeneity of variance and correlated errors and were directly interpretable without back-transformation and associated bias.

\section{DISCUSSION}

A number of tools exist for excluding deer from resources, such as frightening devices (Gilsdorf et al., 2002, Seward et al., 2007), livestock protection dogs (VerCauteren et al., 2008), and fencing (VerCauteren et al., 2006a,b; Brook, 2010). All can be effective when selected based on deer motivation (VerCauteren et al., 2006a,b; Brook, 2010). A substantial physical barrier like a 2.4- to 3.0-m high, woven-wire mesh (e.g., Wisconsin Department of Natural Resources, 2010; Minnesota Department of Natural Resources, 2010) can prohibit passage by deer under, through, or over fencing (VerCauteren et al., 2010), when installed and maintained properly. Such fences are not quick to install, especially in winter, or to move should the need arise. Electric fence designs can provide relatively high levels of deer exclusion, along with rapid deployment and portability (VerCauteren et al., 2006b).

In a review of fence designs for managing deer damage, multistrand electric fences ranged 60 to $80 \%$ and single-strand baited electric fences ranged 80 to $90 \%$ effective for deterring deer access to crops in agricultural settings (VerCauteren et al., 2006b). Protection of stored feed in winter poses greater difficulty because deer may be more motivated to access feed than during summer, and they may be insulated from ground contact by snow. The

Table 3. Group $\times$ period estimated index of deer presence $\left(\hat{\theta}_{m k} \text {, count } / \mathrm{d}\right)^{1}$ and linear contrast estimates of treatment effect $\left(\hat{\delta}_{\text {interaction }}\right)^{2}$ and contrasts of simple effects ${ }^{3}$ from the group|period model to assess efficacy of electric fences for reducing deer presence at artificial feed sites between February 28 and April 5, 2008 in northwestern Minnesota

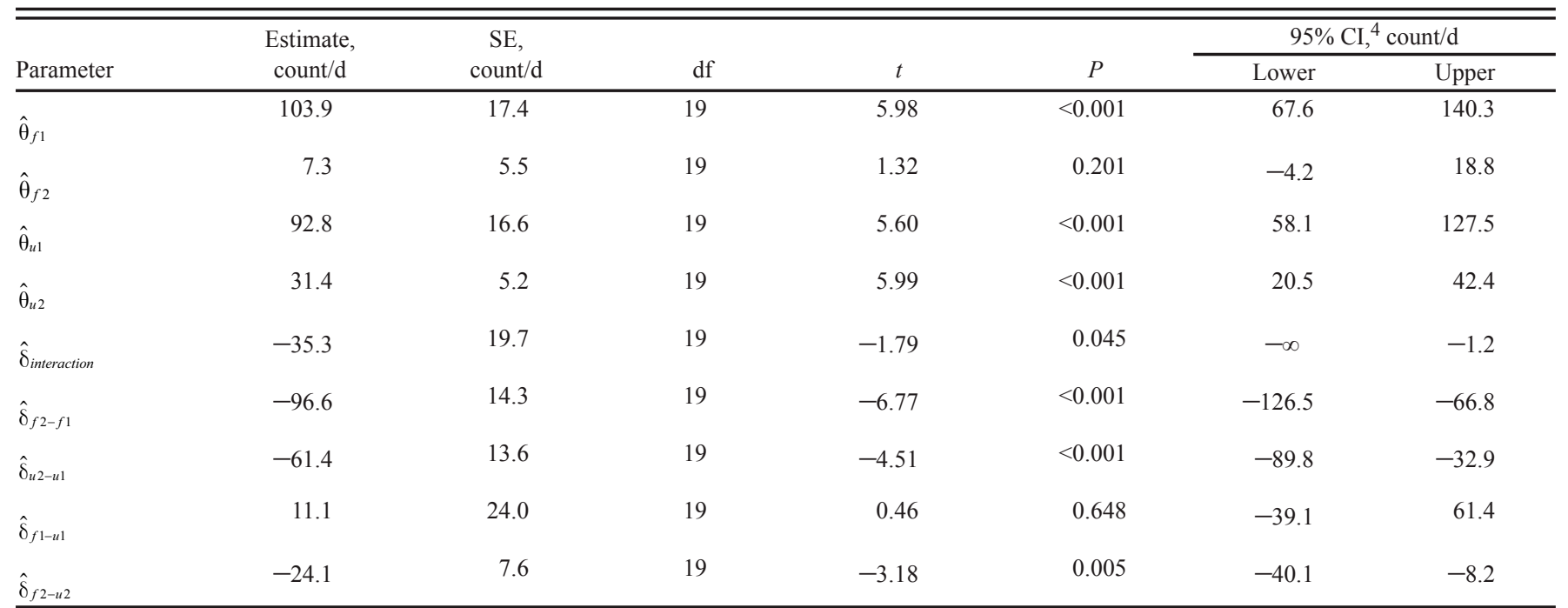

${ }^{1}$ Subscripted $m$ indicates treatment group $(f=$ sites protected by electric fence during treatment period, and $u=$ unprotected sites in either the pretreatment or treatment period), whereas subscripted $k$ indicates period $(1=$ pretreatment, and $2=$ treatment period $)$.

${ }^{2}$ Contrast estimate of treatment effect: $\hat{\delta}_{\text {interaction }}=\left(\hat{\theta}_{f 2}-\hat{\theta}_{u 2}\right)-\left(\hat{\theta}_{f 1}-\hat{\theta}_{u 1}\right)$, representing mean difference between unprotected and protected sites in Period 2 after accounting for differences in Period 1 (negative value indicates relatively greater decline in Period 2 for protected sites). Tests and confidence intervals were 1-tailed because of a priori expectation of decreased deer activity after fencing.

${ }^{3}$ Unplanned post hoc simple main effects contrasts (e.g., $\hat{\delta}_{f 2-f 1}$ ), where levels of 1 fixed effect were contrasted at each level of the other fixed effect in the presence of interaction. Subscripts indicate that values from Period 1 were subtracted from period 2 or values from the unprotected group were subtracted from the protected group; negative values indicate decrease in deer activity in Period 2 or for the protected (fenced) group, respectively.

${ }^{4} \mathrm{CI}=$ confidence interval. 
bipolar fence represented advancement on electric fences tested previously because it eliminated the grounding problem associated with winter use. Furthermore, a wide conductor in a dark brown color was chosen because it was highly visible against a snow-white background. Moreover, the number of strands of bipolar tape, spacing, and fence height were selected to be physically substantial enough to slow approaching deer and encourage them to experience the fence the first time they encountered it, yet be easily installed. It is believed that these features contributed to the efficacy observed for this fence.

Including labor $(7 \mathrm{~h}$ at $\$ 10 / \mathrm{h})$, energizer $(\$ 208)$, battery $(\$ 70)$, fence materials $(\$ 392)$, and bait $(\$ 20)$, these exclosures cost $\$ 760$ each $(\$ 9.50 / \mathrm{m})$. Fence installation required minimal specialized equipment, and the estimated cost $/ \mathrm{m}$ for a larger exclosure would be less assuming 1 energizer/exclosure. In comparison, a 2.4-m high-tensile, woven-wire fence that is permanent would cost $\$ 10$ to $15 / \mathrm{m}$ to install (VerCauteren et al., 2006b). Application of bait required approximately $1 \mathrm{~h} /$ exclosure; however, determination of optimal period for reapplication was beyond the scope of this study.

Significant reductions in deer use of artificial feed piles attributable to the fence were observed, which could translate into reduced transmission risk of bTB from deer to cattle by reducing rate of accumulation and concentration of M. bovis in stored feed. However, risk of disease transmission may remain unacceptably high despite relatively low deer activity at stored feed sites. Although the degree of risk reduction cannot be quantified, even an optimistic assumption of 1-to-1 correspondence between deer presence and transmission risk would imply that the bipolar fence used in this study provided only about $80 \%$ reduction in risk. Therefore, low or 0 risk of $M$. bovis transmission to cattle via feed shared with deer cannot be ensured by this fence and it is not advocated for primary permanent protection of stored feed in areas where bTB occurs. In areas where bTB occurs, the fence could be useful in response to newly developing use of stored feed by deer as an intermediate step toward a more permanent and effective deterrence strategy. For example, the fence could provide temporary protection of stored feed during winter (when installation of permanent fences can be impractical) followed by installation of woven-wire fencing during the subsequent summer.

An important application where the fence could be used without reservation would be protecting against deer depredation of stored feed in areas without bTB, particularly where feed may be stored in different areas among years or where a permanent fence is otherwise undesirable. This fence might also be used to protect other localized resources subject to deer depredation, such as gardens or small orchards.
Future evaluations of this fence should include gradients of baiting intensity (including nonbaited trials), increasing fence height, improving fence design, and evaluation of long-term efficacy, potentially including other seasons when deterrence might be desired. Future research should also evaluate co-implementation of the fence with other management methods, such as kill permits, frightening devices, or guard dogs.

\section{LITERATURE CITED}

Brook, R. K. 2009. Historical review of elk-agriculture conflicts in and around Riding Mountain National Park, Manitoba, Canada. Human-Wildlife Conflicts 3:72-87.

Brook, R. K. 2010. Incorporating farmer observations in efforts to manage bovine tuberculosis using barrier fencing at the wildlifelivestock interface. Prev. Vet. Med. 94:301-305.

Burnham, K. P., and D. R. Anderson. 2002. Model selection and multimodel inference: A practical information-theoretic approach. 2nd ed. Springer, New York.

Carstensen, M., and M. W. DonCarlos. 2011. Preventing the establishment of a wildlife disease reservoir: A case study of bovine tuberculosis in wild deer in Minnesota, USA. Vet. Med. Int. 2011:1-10.

Côté, S. D., T. P. Rooney, J.-P. Tremblay, C. Dussault, and D. M. Waller. 2004. Ecological impacts of deer overabundance. Ann. Rev. Ecol. Evol. Syst. 35:113-147.

Gilsdorf, J. M., S. E. Hygnstrom, and K. C. VerCauteren. 2002. Use of frightening devices in wildlife damage management. Integrated Pest Manag. Rev. 7:29-45.

Hygnstrom, S. E., and S. R. Craven. 1988. Electric fences and commercial repellents for reducing deer damage in cornfields. Wildlife Soc. Bull. 16:291-296.

Jordan, D. M., and M. E. Richmond. 1992. Effectiveness of a vertical 3-wire electric fence modified with attractants or repellents as a deer exclosure. Proceedings of the Eastern Wildlife Damage Control Conf. 5:44-47.

Kinsey, C. 1976. Minnesota Department of Natural Resources. Tests of 2 electric deer barrier forms. Minnesota Wildlife Resources Q. 36:122-137.

Littell, R. C., G. A. Milliken, W. W. Stroup, R. D. Wolfinger, and O. Schabenberger. 2006. SAS for mixed models. 2nd ed. SAS Inst., Cary, NC.

Manly, B. F. J. 1992. The design and analysis of research studies. Cambridge University Press, New York.

Midwestern Regional Climate Center. 2008. Monthly temperature and snowfall for Karlstad, MN. Accessed August 6, 2008. http:// mcc.sws.uiuc.edu/climate_midwest/maps/mn_mapselector.htm. MRCC, Champaign, IL.

Miller, R. A., J. B. Kaneene, S. D. Fitzgerald, and S. M. Schmitt. 2003. Evaluation of the influence of supplemental feeding of whitetailed deer (Odocoileus virginianus) on the prevalence of bovine tuberculosis in the Michigan wild deer population. J. Wildlife Dis. 39:84-95.

Miller, M. W., E. S. Williams, N. T. Hobbs, and L. L. Wolfe. 2004. Environmental sources of prion transmission in mule deer. Emerging Infect. Dis. 10:1003-1006.

Milliken, G. A., and D. E. Johnson. 2009. Analysis of messy data. Volume 1: Designed experiments. 2nd ed. Chapman \& Hall/CRC, Boca Raton, FL. 
Minnesota Department of Natural Resources. 2010. Fencing handbook for 10' woven wire deer exclusion fence. Accessed September 20, 2012. http://files.dnr.state.mn.us/recreation/hunting/deer/bovinetb/fencing_guide.pdf.

O'Brien, D. J., S. M. Schmitt, S. D. Fitzgerald, D. E. Berry, and G. J. Hickling. 2006. Managing the wildlife reservoir of Mycobacterium bovis: The Michigan, USA, experience. Vet. Microbiol. 112:313-323.

O'Rourke, N., L. Hatcher, and E. J. Stepanski. 2005. A step-by-step approach to using SAS for univariate and multivariate statistics. SAS Inst., Cary, NC.

Palmer, M. V., W. R. Waters, and D. L. Whipple. 2004. Investigation of the transmission of Mycobacterium bovis from deer to cattle through indirect contact. Am. J. Vet. Res. 65:1483-1489.

Quinn, G. P., and M. J. Keough. 2002. Experimental design and data analysis for biologists. Cambridge University Press, Cambridge, UK.

Seward, N. W., G. E. Phillips, J. F. Duquette, and K. C. VerCauteren. 2007. Afrightening device for deterring deer use of cattle feeders. J. Wildlife Manag. 71:271-276.

Thompson, B. 2010. Minnesota's bovine tuberculosis management plan. Minnesota Board of Animal Health, St. Paul, USA.

VerCauteren, K. C., M. J. Lavelle, and S. E. Hygnstrom. 2006a. A simulation model for determining cost-effectiveness of fences for reducing deer damage. Wildlife Soc. Bull. 34:16-22.

VerCauteren, K. C., M. J. Lavelle, and S. E. Hygnstrom. 2006b. Fences and deer-damage management: A review of designs and efficacy. Wildlife Soc. Bull. 34:191-200.

VerCauteren, K. C., M. J. Lavelle, and G. E. Phillips. 2008. Livestock protection dogs for deterring deer from cattle and feed. J. Wildlife Manag. 72:1443-1448.

VerCauteren, K., M. Pipas, P. Peterson, and S. Beckerman. 2003. Stored-crop loss due to deer consumption. Wildlife Soc. Bull. 31:578-582.

VerCauteren, K. C., T. R. Vandeelen, M. J. Lavelle, and W. H. Hall. 2010. Assessment of abilities of white-tailed deer to jump fences. J. Wildlife Manag. 74:1378-1381.

Wisconsin Department of Natural Resources. 2010. Captive wildlife. Wisconsin Administrative Code, Chapter NR 16. Accessed June 2, 2010. http://www.legis.state.wi.us/rsb/code/nr/nr016.pdf.

Wobeser, G. A. 2006. Essentials of Disease in Wild Animals. 1st ed. Blackwell Publ., Ames, IA. 